\title{
CÂNCER E AGENTES ANTINEOPLÁSICOS CICLO-CELULAR ESPECÍFICOS E CICLO-CELULAR NÃO ESPECÍFICOS QUE INTERAGEM COM O DNA: UMA INTRODUÇÃO
}

\author{
Vera Lúcia de Almeida, Andrei Leitão, Luisa del Carmen Barrett Reina, Carlos Alberto Montanari e Claudio Luis Donnici* \\ Departamento de Química, Instituto de Ciências Exatas, Universidade Federal de Minas Gerais, \\ CP 702, 31270-901 Belo Horizonte - MG
}

\section{Míriam Teresa Paz Lopes}

Departamento de Farmacologia, Instituto de Ciências Biológicas, Universidade Federal de Minas Gerais, CP 702, 31270-901 Belo Horizonte - MG

Recebido em 3/2/04; aceito em 19/5/04; publicado na web em 9/9/04

\begin{abstract}
CANCER AND CELL CICLE-SPECIFIC AND CELL CICLE NONSPECIFIC ANTICANCER DNA-INTERACTIVE AGENTS: AN INTRODUCTION. The chemotherapy agents against cancer may be classified as "cell cycle-specific" or "cell cycle-nonspecific". Nevertheless, several of them have their biological activity related to any kind of action on DNA such as: antimetabolic agents (DNA synthesis inhibition), inherently reactive agents (DNA alkylating electrophilic traps for macromolecular nucleophiles from DNA through inter-strand cross-linking - ISC - alkylation) and intercalating agents (drug-DNA interactions inherent to the binding made due to the agent penetration in to the minor groove of the double helix). The earliest and perhaps most extensively studied and most heavily employed clinical anticancer agents in use today are the DNA inter-strand cross-linking agents.
\end{abstract}

Keywords: anticancer agents; cycle-(non-)specific agents; DNA inter-strand cross-linking (ISC agents).

\section{CÂNCER: DEFINIÇÕES E ESTATÍSTICAS}

O câncer é uma das doenças que mais causam temor na sociedade, por ter se tornado um estigma de mortalidade e dor. Na verdade, a palavra câncer de origem latina (cancer) significando "caranguejo"1 deve ter sido empregada em analogia ao modo de crescimento infiltrante, que pode ser comparado às pernas do crustáceo, que as introduz na areia ou lama para se fixar e dificultar sua remoção.

Atualmente, a definição científica de câncer refere-se ao termo neoplasia, especificamente aos tumores malignos ${ }^{2}$, como sendo uma doença caracterizada pelo crescimento descontrolado de células transformadas. Existem quase 200 tipos que correspondem aos vários sistemas de células do corpo, os quais se diferenciam pela capacidade de invadir tecidos e órgãos, vizinhos ou distantes.

Estatisticamente, em pesquisa realizada pela Organização Mundial da Saúde, o câncer é a terceira causa de óbitos no mundo com $12 \%$, matando cerca de 6,0 milhões de pessoas por ano. Atualmente, é a segunda causa de mortes por doença no Brasil, estimando-se em 2002, 337.535 casos novos e 122.600 óbitos $^{1,2}$ (Figura 1).

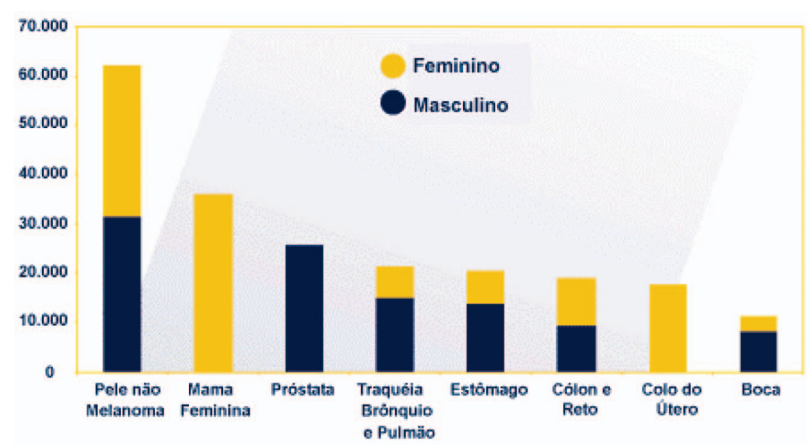

Figura 1. Tipos de câncer mais incidentes, estimados para 2002, na população brasileira

*e-mail: cdonnici@dedalus.lcc.ufmg.br
Os fatores de risco de câncer podem ser encontrados no meio ambiente ou podem ser hereditários ${ }^{2,3}$. A maioria dos casos (cerca de $80 \%$ ) está relacionada ao meio ambiente, onde encontramos um grande número de fatores de risco. Entende-se por ambiente, o meio em geral (água, terra e ar), o ambiente ocupacional (quando insalubre), o ambiente social e cultural (estilo e hábitos de vida) e o ambiente de consumo (alimentos, medicamentos). As mudanças provocadas no meio ambiente pelo próprio homem, os hábitos e estilos de vida adotados pelas pessoas podem determinar os diferentes tipos de câncer $^{1}$. Entretanto, no nosso país, uma representação espaço-geográfica (Figura 2) das taxas brutas de incidência para mulheres e homens (100.000 de cada) estimadas para o ano 2002 segundo a região mostra que é difícil estabelecer uma correlação ambiental que explique as maiores incidências de neoplasia.

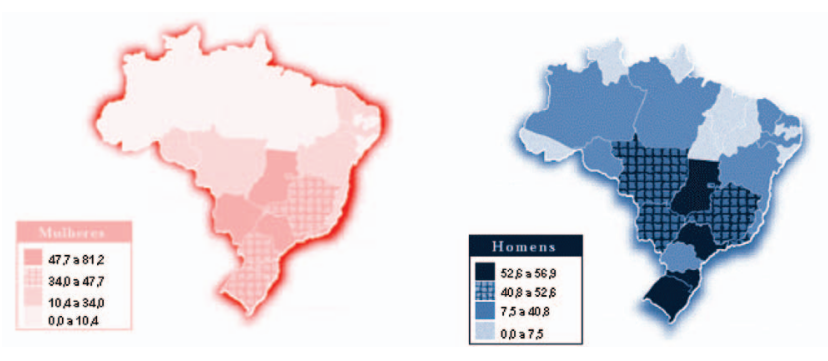

Figura 2. Representação espacial das taxas brutas de incidência por 100.000 mulheres e homens estimada para o ano 2002, segundo a Unidade da Federação (todas as neoplasias)

Como entender bioquimicamente a neoplasia e a sua proliferação? As alterações que geram as neoplasias podem ocorrer em genes especiais denominados protooncogenes, que a princípio são inativos em células normais. Quando ativados, os protooncogenes transformam-se em oncogenes, responsáveis pela malignização (transformação) das células normais (Figura 3$)^{3}$. Estas células diferentes são, então, denominadas cancerosas, ou melhor, tumorais. 


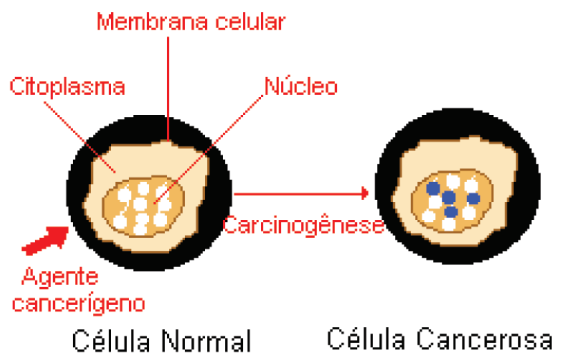

Figura 3. Transformação de uma célula normal em célula cancerosa

Essas células alteradas passam então a se comportar de forma anormal, multiplicando-se de maneira descontrolada. Com a constante multiplicação celular, há a necessidade de que novos vasos sangüíneos sejam formados para que haja a nutrição destas células, em um processo denominado angiogênese. A manutenção e o acúmulo de massa dessas células formam os tumores malignos e elas também podem adquirir a capacidade de se desprenderem do tumor e de migrarem, invadindo inicialmente os tecidos vizinhos, podendo chegar ao interior de um vaso sangüíneo ou linfático e, através destes, disseminarem-se, chegando a órgãos distantes do local onde o tumor se iniciou, formando as metástases ${ }^{2,3}$.

As células cancerosas são, geralmente, menos especializadas nas suas funções que as suas correspondentes normais. Conforme as células cancerosas vão substituindo as normais, os tecidos invadidos vão perdendo suas funções ${ }^{2,3}$; assim por exemplo, a invasão neoplásica dos pulmões gera alterações respiratórias; com isto há a disfunção orgânica que pode levar à falência do órgão ou, em casos mais graves, leva à morte do paciente. Cabe ressaltar que, na verdade, oncologia médica é a especialidade na medicina que foca o tratamento sistemático do paciente com câncer com quimioterapia e outros tipos de tratamento ${ }^{3}$.

\section{PROCESSO DE CARCINOGÊNESE: ESTÁGIOS E CLASSIFICAÇÕES}

O processo de carcinogênese ${ }^{2-4}$, ou seja, de formação de câncer, em geral dá-se lentamente, podendo levar vários anos para que uma célula cancerosa origine um tumor detectável. Esse processo passa por vários estágios antes de chegar ao tumor:

- Estágio de iniciação: É o primeiro estágio da carcinogênese. Nele as células sofrem o efeito de um agente carcinogênico (agente oncoiniciador) que provoca modificações em alguns de seus genes. Nesta fase as células encontram-se geneticamente alteradas, porém ainda não é possível se detectar um tumor clinicamente. Exemplos de substâncias químicas carcinógenas: sulfato de dimetila, metilnitrossuréia, cloreto de vinila, aflatoxinas, dimetilnitrosoamina e benzopireno.

- Estágio de promoção: As células geneticamente alteradas sofrem o efeito dos agentes cancerígenos classificados como oncopromotores. A célula iniciada é transformada em célula maligna, de forma lenta e gradual. Para que ocorra essa transformação, é necessário um longo e continuado contato com o agente cancerígeno promotor. A suspensão do contato muitas vezes interrompe o processo nesse estágio.

- Estágio de progressão: É o terceiro e último estágio e caracteriza-se pela multiplicação descontrolada, sendo um processo irreversível. O câncer já está instalado, evoluindo até o surgimento das primeiras manifestações clínicas da doença.

Os fatores que promovem a iniciação ou progressão da carcinogênese são chamados de carcinógenos ${ }^{3}$. O fumo por exemplo, é um agente carcinógeno completo, pois possui componentes que atuam nos três estágios da carcinogênese.

O câncer é classificado de acordo com o tipo de célula normal que o originou, e não de acordo com os tecidos para os quais se espalhou. Isso é o que pode se chamar de classificação primária ${ }^{2-4}$. Pelo que se sabe sobre classificação primária do câncer, quase todos os tipos podem ser colocados em um dos seguintes grupos, onde o sufixo -oma significa literalmente tumor:

1) Carcinomas: São os tipos mais comuns de câncer, originandose de células que revestem o corpo, incluindo a pele (ectodermais) e uma série de revestimentos internos (endodermais), como os da boca, garganta, brônquios, esôfago, estômago, intestino, bexiga, útero e ovários, e os revestimentos dos dutos mamários, próstata e pâncreas 5 . Há também os carcinosarcomas, tumores geralmente de alta malignidade, derivados de dois tipos de tecidos embrionários e os teratomas, derivados de três tipos de tecidos embrionários ${ }^{2}$.

2) Sarcomas: Originam-se de tecidos de suporte em vez dos de revestimento, tais como ossos, tecido gorduroso, músculo e tecido fibroso de reforço, encontrados na maior parte do corpo.

3) Linfomas: Originam-se de células conhecidas como linfócitos, encontradas em todo o organismo, particularmente em glândulas linfáticas e sangue. Os linfomas são divididos em Hodgkin e não-Hodgkin, de acordo com o tipo de célula afetada.

4) Leucemia: Este câncer origina-se de células da medula óssea que produzem as células sangüíneas brancas. Na leucemia ocorre uma concentração muito elevada de glóbulos brancos (de cerca de $7,5.10^{3} / \mathrm{mm}^{3}$ para $\left.10^{5}-10^{6} / \mathrm{mm}^{3}\right)^{6}$ causando problemas nos quais as células anormais não funcionam apropriadamente, além de restringirem o espaço da medula óssea para que novas células sejam produzidas.

5) Mielomas: Malignidades nas células plasmáticas da medula óssea que produzem os anticorpos.

6) Tumores das células germinativas: Desenvolvem-se a partir de células dos testículos e/ou dos ovários, responsáveis pela produção de esperma e óvulos.

7) Melanomas: Originam-se das células da pele que produzem pigmento, os melanócitos.

8) Gliomas: Originam-se a partir de células do tecido de suporte cerebral ou da medula espinhal. Raramente ocorre metástase.

9) Neuroblastomas: Tumor geralmente pediátrico ( 8 milhões de crianças até 15 anos de idade por ano; $80 \%$ dos casos com até 4 anos de idade) derivado de células malignas embrionárias advindas de células neuronais primordiais, desde gânglios simpáticos até medula adrenal e outros pontos ${ }^{3}$.

\section{TIPOS DE TRATAMENTO - QUIMIOTERAPIA}

Existem três tipos principais de tratamento para o câncer: cirurgia, radioterapia e quimioterapia ${ }^{4,5}$. Mais recentemente tem-se usado a terapia de fotorradiação com derivados hematoporfirínicos (HTP) ${ }^{6}$ e a imunoterapia ${ }^{7}$, sendo que o objetivo de cada um destes tratamentos é erradicar o câncer, normalmente por meio da terapia combinada, onde é associado mais que um tipo de tratamento.

A técnica cirúrgica pode levar à remoção de tumores com eficácia, se não houver metástase; no caso da leucemia por exemplo, costuma ser necessário o uso de outros tipos conjuntos de terapia ${ }^{5}$, incluindo o transplante de medula. A radioterapia (geralmente raios gama, radioisótopos como cobalto-60, raios-X e até prótons e mésons pi negativos) é usada comumente em conjunto com a cirurgia, com incremento da eficiência do tratamento. Mesmo isoladamente, a radioterapia pode diminuir tumores grandes, diminuir a recorrência e a chance de metástase, sendo uma metodologia antineoplásica muito 
usada; entretanto, mesmo que sejam usados os sensitizadores (que diminuem os efeitos colaterais) o tratamento por radiação é sujeito a severas limitações 5 .

A técnica antineoplásica de fotorradiação $0^{6,7}$ é um importante avanço, pois permite a localização e a destruição com maior seletividade pelo uso de radiação específica com fluorescência ( $\lambda$ de $620-640 \mathrm{~nm}$ ), para detecção e destruição de tumores com uso de fibras óticas. Contudo, pelo acúmulo de porfirinas em órgãos normais ainda não se obtém uso clínico interno, só em tumores superficiais. Atualmente, o tratamento antineoplásico tem usado o estímulo das próprias defesas do corpo pela imunoterapia, com o interferon $\alpha$, interleucina-2 e mesmo o BCG (Bacillus Calmette Guédes) mas, apesar de promissora, a imunoterapia é ainda uma técnica antineoplásica adjuvante, usada especialmente para destruir as células cancerosas residuais após intervenção cirúrgica ou outro tratamento ${ }^{6}$.

Com esses métodos de tratamento citados, um terço dos pacientes consegue ser curado através de medidas locais (cirurgia ou radioterapia), que são eficazes quando o tumor ainda não sofreu metástase por ocasião do tratamento. Todavia, nos demais casos, a neoplasia caracteriza-se pelo desenvolvimento precoce de micrometástases, indicando a necessidade de uma abordagem sistêmica, que pode ser efetuada, em cerca de $60-70 \%$ dos $\operatorname{casos}^{3}$ com a quimioterapia, que será abordada mais detalhadamente neste trabalho. Cabe ressaltar, que não se abordará neste texto os agentes antineoplásicos biorredutíveis, geralmente usados para tratamento de tumores sólidos, que foram tratados em revisão recentemente publicada ${ }^{8}$.

O objetivo primário da quimioterapia é destruir as células neoplásicas, preservando as normais. Entretanto, a maioria dos agentes quimioterápicos atua de forma não-específica, lesando tanto células malignas quanto normais ${ }^{5,7}$, particularmente as células de rápido crescimento, como as gastrointestinais, capilares e as do sistema imunológico. Isto explica a maior parte dos efeitos colaterais da quimioterapia: náuseas, perda de cabelo e susceptibilidade maior às infecções ${ }^{6,8}$. Porém, o corpo recupera-se destes inconvenientes após o tratamento, e o uso clínico desses fármacos exige que os benefícios sejam confrontados com a toxicidade, na procura de um índice terapêutico favorável ${ }^{4,5,7}$. Um fator importante para o êxito da quimioterapia é a precocidade no diagnóstico do tumor ${ }^{3}$ (entre $10^{9}$ e $10^{12}$ células tumorais, ou seja, tumor com tamanho inferior a $1 \mathrm{~cm}$ ).

Assim, é desejável na quimioterapia usar doses mais altas, capazes de atingir o maior nível de morte celular possível; considerando-se um tumor de $1 \mathrm{~g}$ (cerca de $10^{9}$ células) cada ciclo de terapia mata cerca de $99 \%$ das células; é imprescindível repetir-se o tratamento em múltiplos ciclos para matar todas as células tumorais9. Porém, em tumores maiores, por exemplo de $100 \mathrm{~g}$ ( $10^{11}$ células), mesmo com a eficiência do agente antineoplásico de 99,9\%, ainda ter-se-iam células cancerosas demais para a continuidade eficiente do tratamento, o que corrobora a necessidade preemente do diagnóstico neoplásico precoce. Nos casos mais favoráveis, com a quimioterapia atual, pode-se obter maior expectativa de vida, tendo-se em diversos casos até cerca de $66 \%$ de pacientes livres do câncer por mais de 10 anos. No caso dramático do linfoma de Burkitt, que mata milhares de crianças na África, em até três meses após o início da metástase, pode-se ter a cura plena de $60 \%$ dos doentes, com quimioterapia especializada. Muitos estudos estão sendo feitos para a maior eficiência da quimioterapia e a combinação de diversos agentes antineoplásicos, tendo-se conseguido resultados surpreendentes com índices de cura de 75 a $90 \%$ em diversos tipos de câncer. Sendo assim, é importante que se esteja informado sobre os aspectos químicos e bioquímicos destes quimioterápicos e traz-se neste artigo um breve relato sobre os principais agentes antineoplásicos mais usados.

\section{CLASSIFICAÇÕES DE QUIMIOTERÁPICOS ANTINEOPLÁSICOS}

A importância clínica dos agentes antineoplásicos induz a necessidade de estudo sistemático, o que primeiramente deveria ser feito com o uso de classificações químicas, levando-se em conta os diferentes grupos funcionais presentes na estrutura das moléculas dos agentes anticancerígenos. Contudo, a variedade de tipos de compostos utilizados em quimioterapia oncológica é tão grande, que tal classificação só pode ser feita indiretamente. Calabresi e Chabner, em texto clássico ${ }^{9}$, descreveram uma classificação conveniente dos fármacos antineoplásicos onde o critério classificatório baseia-se no ponto de interferência no mecanismo de ação das diferentes etapas da síntese do DNA, transcrição e transdução (Figura 4). Entretanto, os autores consideram esta classificação arbitrária pois, por exemplo, os agentes hormonais, entre outros, não são classificáveis desta forma.

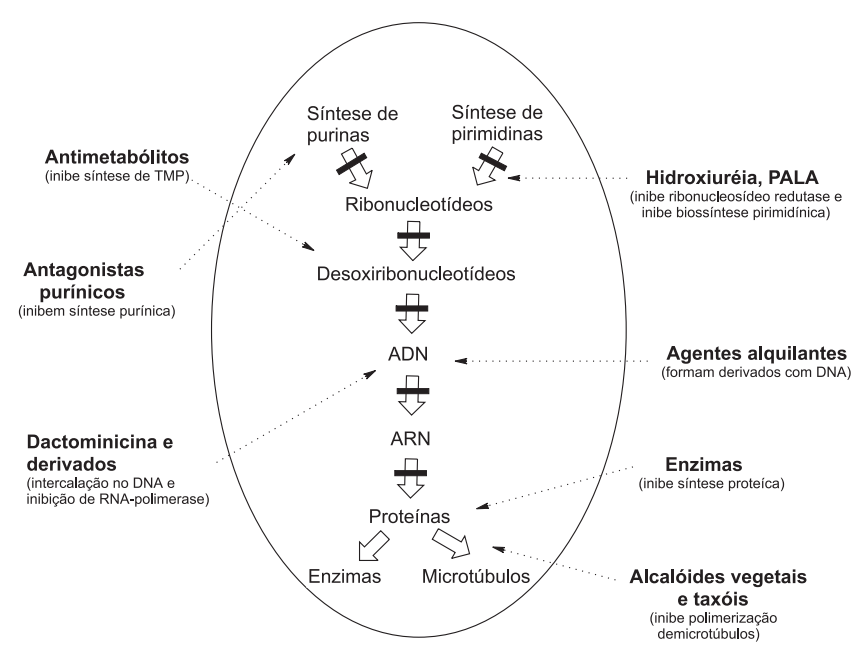

Figura 4. Classificação de agentes antineoplásicos de Calabresi e Chabner

De fato, existem diversos mecanismos que estão envolvidos na evolução de uma célula normal para uma célula potencialmente ma$\operatorname{ligna}^{10}$, mas a maior parte deles interferem na divisão celular e, assim, o conhecimento do ciclo celular ou dos seus mecanismos é importante para que haja a compreensão da etiologia do câncer ${ }^{7}$ (Figura 5a). A Figura 5b, mostra uma correlação aproximada dos ciclos metabólicos com os tipos de agentes quimioterápicos antineoplásicos ${ }^{3}$ mais comuns.

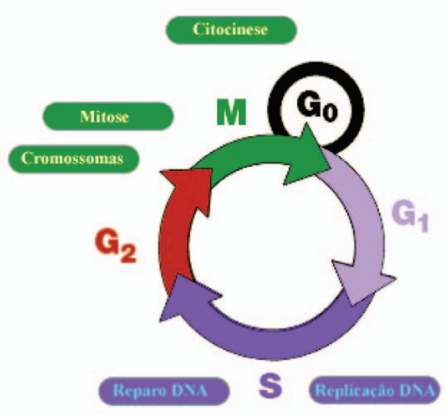

Figura 5a. Ciclo de replicação celular esquemático para célula em mitose

A célula que não está replicando apresenta-se na fase $\mathrm{G}_{0}$. Nesta fase, o DNA apresenta-se super-enovelado, com atividade nuclear 


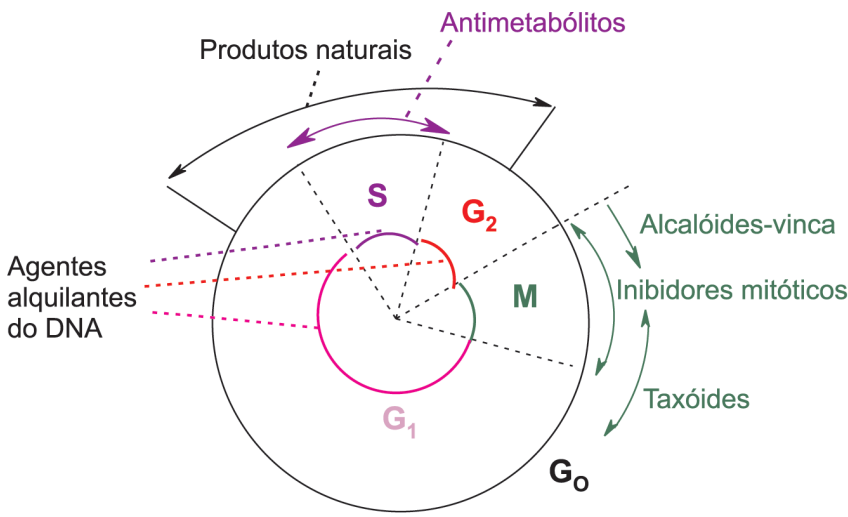

Figura 5b. Atividade dos agentes quimioterápicos antineoplásicos, dependendo da fase do ciclo celular

baixa. Este estágio pode ser modificado para a fase $\mathrm{G}_{1}$, onde há a preparação da célula para a multiplicação, com a produção de constituintes celulares que serão essenciais para a nova célula que será gerada, além da preparação para a síntese de DNA, que ocorrerá na fase $\mathrm{S}$.

Nas fases $\mathrm{G}_{1}$ e $\mathrm{S}$ existem diversos mecanismos reguladores que irão afetar a multiplicação celular. Os fatores de crescimento, como os produtos de oncogenes, ativam a multiplicação celular, enquanto que os controles de retroalimentação ("feedback") são inibidores da multiplicação celular. Estes controles são, por exemplo, genes supressores tumorais, que detém a replicação celular quando há dano no DNA, para que ele seja reparado ${ }^{7}$. As interleucinas, dentre outras substâncias, também afetam a replicação celular, entretanto seus mecanismos são obscuros. Outro mecanismo regulador é a apoptose (morte celular programada), que provoca a morte da célula em detrimento da possibilidade da célula tornar-se alterada, podendo levar ao câncer ${ }^{11}$. Na fase $\mathrm{G}_{2}$ há a síntese de componentes para a mitose (divisão celular com manutenção do número de cromossomos específico da espécie) como a produção do fuso mitótico que é feita na fase M. Após a divisão do material nuclear há a citocinese (que é a separação da célula mãe, formando as duas células filhas com suas organelas e demais constituintes celulares), finalizando o ciclo de replicação celular (retorna à fase $\mathrm{G}_{0}$ ). A célula tumoral ou transformada não finaliza o ciclo de replicação celular (não retorna à fase $\mathrm{G}_{0}$ ), assim passa da fase $M$ para nova fase $\mathrm{G}_{1}$.

Muitos fármacos eficazes contra o câncer exercem sua ação sobre as células que se encontram no ciclo celular, e são denominados fármacos ciclo-celular específicos (CCS) (Tabela 1). Um segundo grupo de agentes, denominados fármacos ciclo-celular não específicos (CCNS), tem a capacidade de exterminar as células tumorais independentemente de estarem atravessando o ciclo ou de estarem em repouso no compartimento $\mathrm{G}_{0}(\text { Tabela } 1)^{5,7,9}$.

Apesar deste trabalho tratar somente de agentes antineoplásicos que interagem com o DNA, cabe ao menos citar alguns outros tipos de agentes, como os hormonais e os produtos naturais ciclo-celular específicos. Os agentes hormonais não são citotóxicos, por serem modulares de proliferação celular, e devem ser classificados à parte; a ação hormonal depende de ligações entre o hormônio e o seu receptor citoplasmático específico. Esta ligação provoca a síntese de RNA mensageiro que, por sua vez, direciona a síntese de novas proteínas importantes para o crescimento e a multiplicação celular. A atividade antitumoral de vários agentes hormonais depende da mesma seqüência de eventos, por vezes interferindo e bloqueando estes processos $^{6}$. Por exemplo, hormônios sexuais são utilizados no tratamento do câncer das glândulas mamárias e próstata. Os hormônios sexuais estão relacionados com a estimulação, controle da prolifera- ção e função destes tecidos; de fato, o câncer pode ser inibido ou estimulado por alterações apropriadas no equilíbrio hormonal ${ }^{8}$.

Os produtos naturais ciclo-celular específicos são outro tipo de agente antineoplásico importante e eficiente, e que se refere a muitos fármacos usados na terapia clínica do câncer e que originalmente não são compostos sintéticos. Dentre alguns produtos naturais citotóxicos, usados clinicamente no tratamento de neoplasias, têmse os alcalóides vegetais (produtos naturais nitrogenados derivados biossinteticamente de aminioácidos) como: $i$ ) alcalóides da vinca (vimblastina e vincristina) ${ }^{8}$ (Figura 6) - ação pela inibição do fuso mitótico, ligando-se às proteínas microtubulares e, conseqüentemente, interrompendo a divisão celular na metáfase ${ }^{8}$; ii) taxol (Figura 6), éster alcalóide derivado do teixo ocidental (Taxus brevifolia) e do teixo europeu (Taxus baccata), (conhecido comercialmente como Paclitaxe $\left.1^{\circledR}\right)^{8}$ - ação também pela inibição do fuso mitótico, dimerização da tubulina e estabilização dos túbulos, protegendo-os da despolimerização, o que estabiliza resulta no bloqueio da multiplicação celular, o que resulta na perda da viabilidade celular'; iii) podofilotoxinas (ou epipodofilotoxinas) ${ }^{7-9}$, tendo-se como exemplos principais a etoposida (VP-16) e teniposida (VM-26), Figura 6, derivados semi-sintéticos da podofilotoxina, extraída da raiz do podofilo (Podophyllum peltatum $)^{7-9}$ - ação pelo bloqueio das células nas fases $\mathrm{S}$ e $\mathrm{G}_{2}$ e inibição da enzima topoisomerase II, o que promove lesão no DNA. Pode-se citar também o uso da enzima asparaginase (Lasparagina amino hidrolase, Elspar), particularmente em tratamento de leucemia aguda infantil ${ }^{6-9}$, isolada de várias bactérias, que atua pela diminuição catabólica de asparagina sérica, assim como dos níveis sanguiíneos de glutamina. Nas células neoplásicas, isto provoca a inibição da síntese de proteínas, resultando no bloqueio da proliferação celular. Por último é digno de nota ressaltar o uso recente de vacinas antitumorais, ainda em fase de teste, através da interação antígeno-anticorpo visando a imunização do organismo ${ }^{12}$.
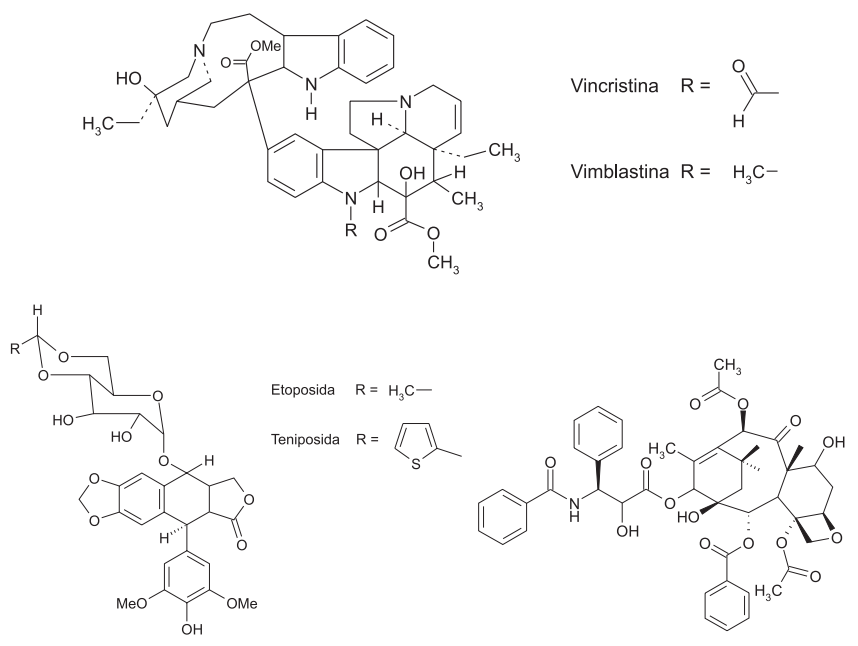

taxol

Figura 6. Estruturas de vimblastina, vincristina, etoposida, teniposida e taxol

Os agentes antineoplásicos mais antigos e mais usados são conhecidos como agentes alquilantes que, comprovadamente, interagem quimicamente com o DNA e não são ativos somente no processo de divisão celular. De fato, na quimioterapia são descritos muitos alvos que podem ser estudados com o intuito de se estabelecer novos fármacos antitumorais, sendo que o DNA apresenta-se como um dos alvos mais estudados ${ }^{13-16}$. As moléculas com potencial atividade antitumoral citadas mais detalhadamente neste trabalho atuam no DNA (Figura 7). 
a)<smiles>OC1CCOC1O</smiles>

Desoxirribose

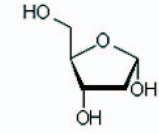

Ribose

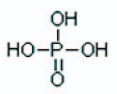

Ácido fosfórico b)
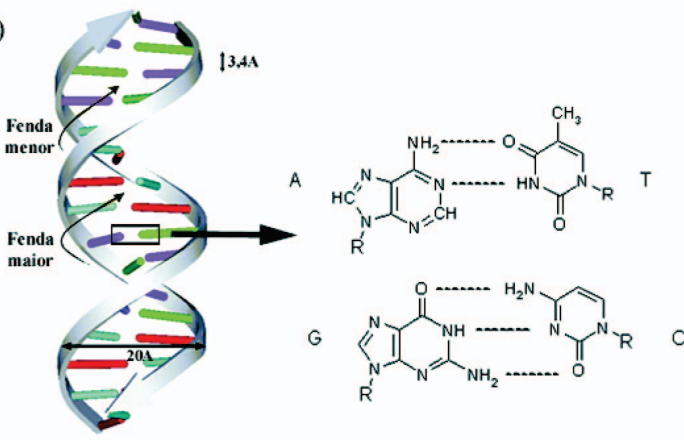

Figura 7. A estrutura do DNA, adaptada da ref. 17

a) o açúcar que compõe o DNA (desoxirribose), o RNA (ribose) e o ácido fosfórico;

b) a fita dupla do DNA, mostrando as fendas menor e maior, além das ligações hidrogênio entre os pares de base nitrogenadas Adenina (A), Timina (T), Citosina (C) e Guanina (G).

O DNA também apresenta variações estruturais (isoformas) dependentes do meio onde se encontra ${ }^{16}$, Figura 8a:

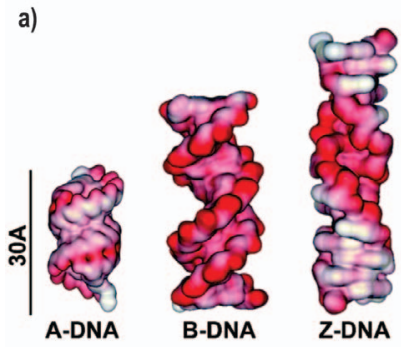

b)

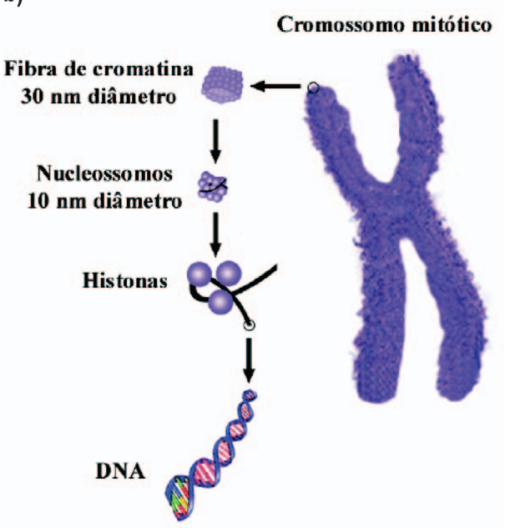

Figura 8. Estrutura do DNA na forma super-helicoidal: a) as três isoformas do DNA; b) o DNA super-helicoidal, adaptadas da ref. 17

- B-DNA: é a forma fisiológica mais encontrada, onde as interações com as bases nitrogenadas promovem a formação da dupla hélice com rotação para a direita e das fendas menor e maior, seu diâmetro é de aproximadamente $20 \AA$, com espaçamento entre os pares de base de $3,4 \AA$;
- A-DNA: esta isoforma do DNA está presente em meio com baixa concentração de água, apresentando diâmetro de aproximadamente 26 Å e espaçamento entre os pares de base de 2,7 ̊̊;

- Z-DNA: possui a rotação da hélice para a esquerda, sendo bem diferente das outras duas isoformas. Já foram detectados fragmentos de Z-DNA em alguns organismos procariotas e eucariotas. O DNA também está enovelado em uma estrutura chamada superhelicoidal (Figura 8b). Macromoléculas, como as histonas, servem como base para que o DNA possa estar superenovelado.

\section{ANTINEOPLÁSICOS E INTERAÇÃO COM O DNA}

Como mostrado na Tabela 1, os antineoplásicos ${ }^{17}$, são fármacos quase tão heterogêneos (quando consideradas suas características químicas e mecanismos farmacológicos) quanto os tumores envolvidos. De fato, diversos antitumorais muito utilizados clinicamente são substâncias que apresentam mecanismo de ação ciclo-celular nãoespecífico e relacionado ao DNA (tipos como produtos naturais, complexos de coordenação de platina, agentes alquilantes e agentes intercalantes) mas, mesmo dentro desta subclasse tem-se grande heterogeneidade e é possível fazer uma subclassificação dos antitumorais em relação ao mecanismo de ação no DNA ${ }^{18}$ :

- inibição da síntese de nucleotídeos: através do uso dos análogos das bases nitrogenadas;

- efeito direto no DNA: são os agentes alquilantes ${ }^{19}$ como as mostardas nitrogenadas, nitrossuréias, complexos tipo cisplatina e outros. A bleomicina forma radicais livres que destroem o DNA, pois fragmenta as hélices, mecanismo diferente dos outros fármacos mostrados;

- ligantes que interagem na fenda menor do DNA ${ }^{20}$ : berenil, pentamidina e análogos;

- alterando as propriedades de pareamento das bases: intercalantes $^{21-23}$ como a proflavina, acridina, amsacrina;

- inibindo a DNA-girase: doxorrubicina ${ }^{7}$;

Assim, em uma classificação mais pormenorizada e ampla de agentes antineoplásicos que interagem com o DNA deve-se apresentálos de maneira fiel às diferenças nos mecanismos de ação, delineados a seguir.

\section{QUIMIOTERÁPICOS ANTINEOPLÁSICOS CICLO- CELULAR ESPECÍFICOS (CCS) POR AÇÃO METABÓLICA BLOQUEADORA DA SÍNTESE DE DNA}

\section{Agentes antimetabólitos}

O desenvolvimento de fármacos com ações sobre o metabolismo intermediário das células em proliferação é importante do ponto de vista clínico, pois estes agentes são muito estudados e clinicamente empregados. Embora não se tenha ainda descoberto qualquer propriedade bioquímica peculiar compartilhada por todas as células cancerosas, as células neoplásicas possuem várias diferenças metabólicas quantitativas em comparação com as células normais, tornando-as mais suscetíveis aos diversos antimetabólicos ou análogos estruturais das bases nitrogenadas ${ }^{8}$.

Os agentes antimetabólicos (Figura 9) exercem seus efeitos principalmente por bloquearem bioquimicamente a síntese do DNA e, portanto, são restritos à fase $\mathrm{S}$ do ciclo celular ${ }^{5,6,8}$. Pode-se citar alguns exemplos de antimetabólicos utilizados clinicamente no tratamento do câncer, por meio das seguintes subclasses (Figura 9):

Análogo do ácido fólico: Metotrexato (MXT);

Antagonistas das pirimidinas: Fluorouracil (5-Fluoroouracil; 5FU) e Floxuridina (5-Fluorodesoxiuridina; FUDR); Citarabina (citosina arabinosídeo, ara-C). 
Análogos das purinas:Mercaptopurina (6-mercaptopurina; 6-MP); tioguanina (6-tioguanina;TG); Pentostatina (2'-desoxicoformicina); Fosfato de fludarabina (mono fosfato de 2-fluoro-arabinofuranosiladenina; Cladribina (2-clorodesoxiadenosina).<smiles>Nc1nc(S)c2nc[nH]c2n1</smiles>

6-mercaptopurina 6-tioguanina<smiles>O=c1[nH]cc(F)c(=O)[nH]1</smiles>

Fluoracil

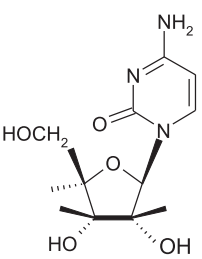

5-azacitidina<smiles>CC(C(=O)O)N(CCCC(=O)O)C(=O)c1ccc(N(C)Cc2cnc3nc(N)nc(N)c3n2)cc1</smiles>

Metotrexato é que os antitumorais mais usados e estudados são agentes que geralmente atuam como eletrófilos sobre macromoléculas nucleofílicas, particularmente o DNA (Figura 7). Contudo, apesar de se admitir que estes agentes não são ciclo-celular específicos, já se observou que as células são mais sensíveis à alquilação nas fases $G_{1}$ e $S$ do ciclo celular, apresentando bloqueio em $\mathrm{G}_{2}{ }^{3,7}$. Estes agentes antitumorais formam comprovadamente ligações cruzadas ("CrossLink”) com as fitas ou filamentos do DNA ${ }^{10}$, podendo-se observar, como ilustrado na Figura 10, os diferentes tipos de ligações cruzadas que podem ocorrer. Todas estas ligações produzem lesões no DNA, sendo que as provocadas pelas ligações cruzadas interfilamentares ("InterStrand Cross-link - ISC") são as mais citotóxicas, pois a alquilação de um único filamento de DNA pode até ser reparada facilmente, mas as ligações cruzadas interfilamentares, como as produzidas por agentes alquilantes bifuncionais, exigem mecanismos mais complexos de reparação, podendo até inibir sua replicação ${ }^{10}$. Há diversas classes de agentes antineoplásicos que têm este tipo de mecanismo de ação ${ }^{10}$, como os antitumorais mostrados a seguir, que serão abordados em relação às possíveis ligações cruzadas interfilamentares com o DNA.

Cabe ressaltar, primeiramente, que esses agentes alquilantes são fortes reagentes eletrofílicos, como esquematizado na Figura 10 e

Figura 9. Estruturas de alguns antimetabólitos usados no tratamento de neoplasias

\section{QUIMIOTERÁPICOS ANTINEOPLÁSICOS CICLO- CELULAR NÃO-ESPECÍFICOS (CCNS) QUE INTERAGEM COM O DNA POR FORMAÇÃO DE LIGAÇÕES CRUZADAS}

Conforme relatado, apesar de que até agora tem-se postulado que a atividade de fármacos anticancerígenos pode ser classificada somente em agentes ciclo-celular específicos (CCS) ou ciclo-celular não específicos (CCNS), observou-se mais recentemente ${ }^{19,24}$ que dentre estes últimos, o fator mais importante para a atividade antitumoral e potencialidade para seu uso no tratamento das diferentes neoplasias,
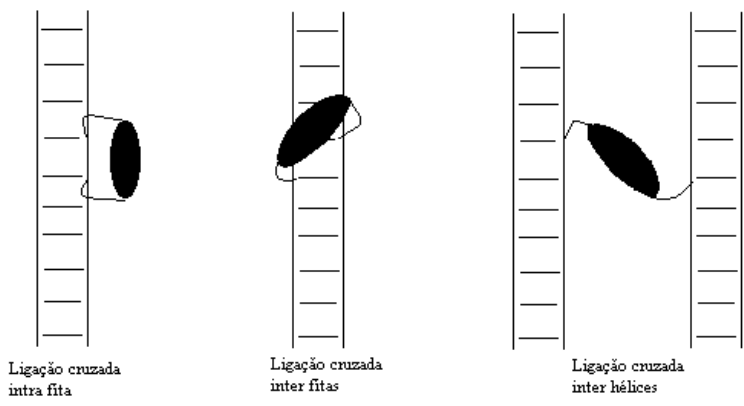

Figura 10. Algumas das ligações cruzadas que podem ocorrer entre um agente alquilante bifuncional e o DNA

Tabela 1. Relações entre ciclo celular e principais classes de agentes antineoplásicos ${ }^{6-9}$

1. Agentes ciclo-celular específicos (CCS, "Cell Cycle-Specific")

1.1. Agentes Antimetabólitos

1.1.a. Análogo do ácido fólico

1.1.b. Antagonistas das pirimidinas

1.1.c. Análogos das purinas e inibidores correlatos

1.2. Agentes Hormonais

1.2.a. Adrenocorticosteróides

1.2.b. Progestinas

1.2.c. Estrogênios

1.2.d. Androgênios

1.2.e. Antiestrogênio

1.2.f. Antiandrogênio

1.2.g. Análogo do hormônio liberador de gonadotropina

1.2.h. Inibidor da aromatase

1.2.i. Inibidor do hormônio peptídico

1.3. Produtos Naturais

1.3.a. Alcalóides vegetais

1.3.a.1. Alcalóides da vinca

1.3.a.2. Podofilotoxinas (Epipodofilotoxinas)

1.3.a.3. Paclitaxel (Taxol)
2. Agentes ciclo-celular não específicos (CCNS, "Cell Cycle-NonSpecific")

2.1. Produtos Naturais

2.1.a. Antibióticos naturais

2.1.a.1. Antraciclinas

2.1.a.2. Mitomicina

2.1.a.3. Dactinomicina

2.1.a.4. Plicamicina

2.1.a.5. Bleomicina

2.1.b. Alcalóides pirrolizidínicos

2.2. Complexos de Coordenação de Platina

2.2.a. Cisplatina (cis-DDP)

2.2.b. Carboplatina (CBDCA)

2.3. Agentes Alquilantes Diversos

2.3.a. Mostardas nitrogenadas

2.3.b. Nitrossuréias

2.3.c. Triazenos

2.3.d. Alquil sulfonatos 
no Esquema 1, formando ligações covalentes por reação de alquilação com centros nucleofílicos do DNA, principalmente as bases purínicas e pirimidínicas. Estudos mais específicos de reatividade mostram o isolamento e a caracterização de adutos entre alguns agentes alquilantes e o DNA ${ }^{19,24}$, como em alguns exemplos mostrados no Esquema 1. A eficiência da ação de agentes alquilantes já foi estudada por modelagem molecular ${ }^{25-26} \mathrm{e}$ outros estudos de planejamento racional $^{27,28}$ que evidenciam a correlação entre a distância intramolecular dos centros eletrofílicos destes agentes alquilantes e a distância dos centros nucleofílicos nucleotídicos nitrogenados. Con tudo, apesar desta correlação estrutural, a presença de outros grupos nucleofílicos como os grupos amino, sulfidrila, hidroxila em outras moléculas biológicas, também alquiláveis, explica os efeitos tóxicos destes agentes.

\section{Mostardas nitrogenadas}

$\mathrm{Na}$ verdade, os agentes alquilantes são antineoplásicos pionei$\operatorname{ros}^{19,24}$ pois, em 1942, o agente alquilante tipo mostarda nitrogenada, meclorometamina, foi utilizado com sucesso para induzir remissão tumoral transitória em um paciente portador de linfoma; este acontecimento marcou o início da era moderna de quimioterapia do câncer. Os agentes alquilantes são, também, os antineoplásicos mais estuda$\operatorname{dos}^{24,29}$ e considerados os agentes antitumorais mais usados na atualidade. Eles são capazes de formar ligações interfilamentares com o DNA e necessitam ser metabolizados pelas fosfamidases (enzimas microssomais hepáticas), para que seus metabólitos possam exercer o efeito alquilante celular ${ }^{29}$. O principal sítio de alquilação no DNA é a posição N7 da guanina, porém outras bases podem ser menos extensivamente alquiladas, como a adenina nas posições N1 e N3, a citosina no N3 e a guanina no O6, assim como grupos fosfatos e proteínas associadas ao DNA. Dentro desta classe têm-se os fármacos
Mecloretamina (Mustargen ${ }^{\circledR}$ ) e Clorambucil (Leukeran ${ }^{\circledR}$ ), além da ciclofosfamida $\left(\right.$ Cytoxan $\left.^{\circledR}\right)$, a Isofosfamida ${ }^{\circledR}$ e o melfalam ${ }^{7,9}$ $\left(\right.$ Alkeran $\left.^{\circledR}\right)$.

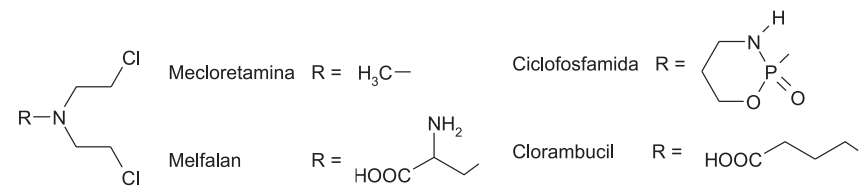

Figura 11. Estruturas de mostardas nitrogenadas usadas como quimioterápicos

\section{Nitrossuréias}

São agentes antitumorais que precisam ser biotransformados nos seus derivados alquilantes por decomposição não enzimática ${ }^{7}$. Formam diferentes adutos de alquilação com o DNA, porém a formação da ligação cruzada interfilamentar entre a posição N1 da deoxiguanosina e N3 da deoxicitosina é a responsável pela atividade citotóxica $^{30}$. Também alquilam o RNA e inibem a auto-reparação do DNA ${ }^{8}$. As nitrossuréias utilizadas clinicamente são a Carmustina (BCNU), Lomustina (CCNU) e Semustina (metil-CCNU) ${ }^{7-9}$ (Figura 12). Estes agentes antineoplásicos são altamente lipossolúveis, tornando-os úteis no tratamento de tumores cerebrais ${ }^{7,31}$.

\section{Triazeno}

Inicialmente considerado um antimetabólito, o derivado triazeno Dacarbazina (DTIC) (Figura 12), funciona através de alquilação do DNA. A Dacarbazina exige ativação inicial pelo citocromo P-450, através de uma reação de N-desmetilação. Na célula alvo, a clivagem
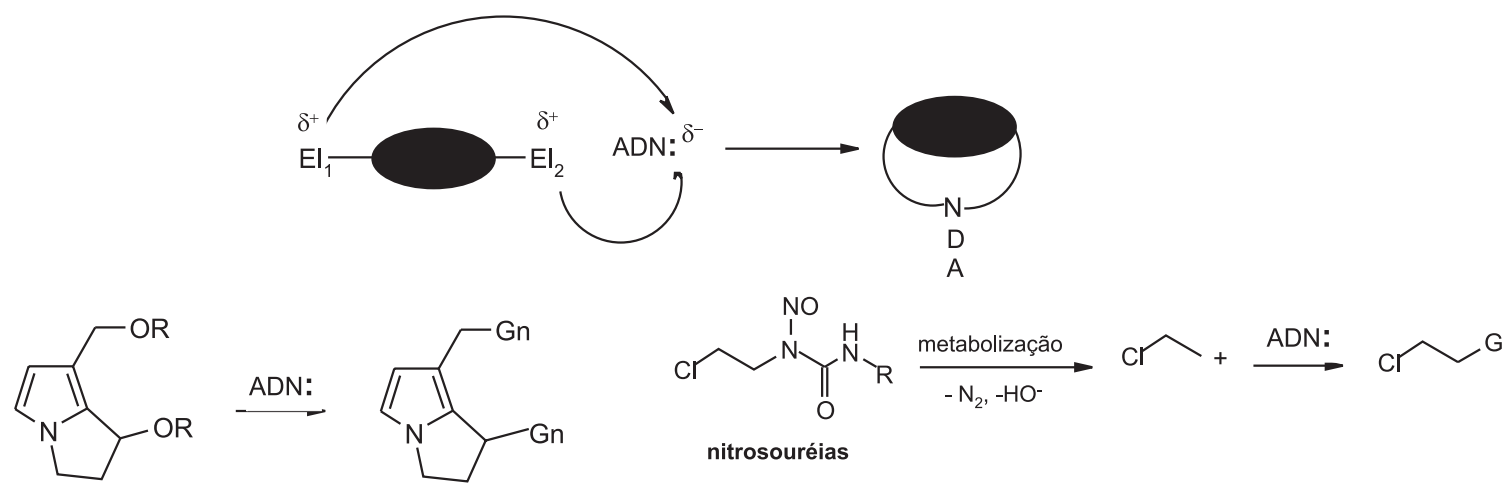

alcalóides pirrolizidínicos
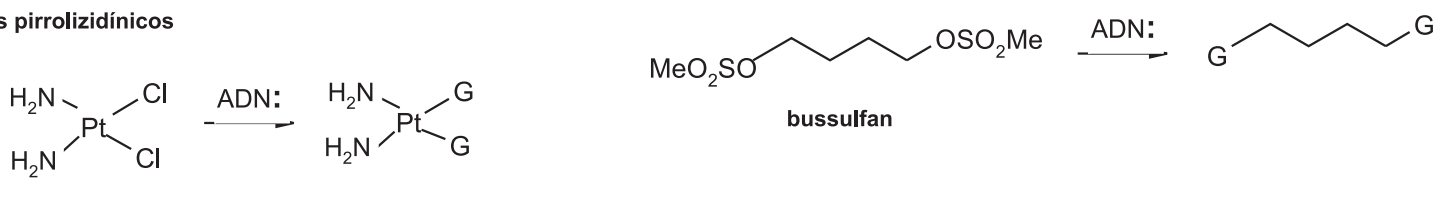

cis-platina<smiles>COC(C)CCl</smiles><smiles>[N+]#[W]</smiles><smiles>[CH]CCN(C)CC[Hg]</smiles><smiles>Nc1nc2[nH]cnc2c(=O)[nH]1</smiles>

$G=$ guanina<smiles>Nc1nc2c(ncn2[C@@H]2O[C@H](CO)[C@@H](O)[C@H]2O)c(=O)[nH]1</smiles>

$\mathrm{Gn}=$ guanosina 
espontânea do metabólito libera um componente alquilante, o diazometano 9 .
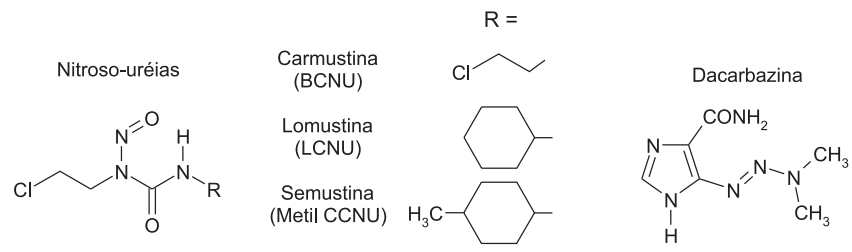

Figura 12. Estruturas de nitrossuréias e Dacarbazina, usados como antitumorais

\section{Alquilsulfonatos}

São agentes alquilantes derivados dos ésteres alcanossulfônicos. Muitos destes compostos são ativos sobre numerosas células cancerosas, porém o mecanismo exato pelo qual exercem seu efeito citotóxico não está totalmente elucidado ${ }^{32}$. O fármaco Busulfan ${ }^{\circledR}$ $\left(\right.$ Myleran $^{\circledR}$ ) (Figura 13) e seus homólogos congêneres são os únicos compostos dissulfonílicos que se têm mostrado capazes de formar ligações cruzadas interfilamentares com o $\mathrm{DNA}^{33}$. Uma subclasse interessante que deve ser citada é a dos 2-cloroetil-metanossulfonatos. $\mathrm{O}$ [(2-cloroetil-sulfonil)-metil] metanossulfonato (clomesona) (Figura 13), apesar de apresentar atividade citotóxica menor que a do Bussulfan e congêneres, tem-se mostrado mais seletivo em relação ao DNA, quando comparado com as nitrossuréias ${ }^{34}$.<smiles>CS(=O)(=O)OCCCCOS(C)(=O)=O</smiles><smiles>CS(=O)(=O)OCOS(=O)(=O)CCCl</smiles>

Figura 13. Estruturas de alquil sulfonatos biologicamente ativos

\section{Complexos de coordenação de platina}

Os antineoplásicos formados por compostos de coordenação com platina, como a cisplatina (cis-DDP, comercialmente Platinil ${ }^{\circledR}$, ou Platinol $^{\circledR}$ ) e carboplatina (CBDCA, Paraplatin ${ }^{\circledR}$ ) (Figura 14), alquilam o DNA. O mecanismo de ação está relacionado com a inibição seletiva da síntese do $\mathrm{DNA}^{6,8,9}$. As propriedades citotóxicas destes compostos, assim como de numerosos análogos, têm sido atribuídas à sua habilidade de formar ligações cruzadas do tipo interfilamentares como também intrafilamentares ${ }^{10}$. Mais recentemente, tem-se dado particular ênfase à capacidade da cisplatina em provocar mutações no DNA $^{35}$ e alterar a ligação DNA-proteína ${ }^{36,37}$. Os complexos de platina parecem ter efeito sinérgico com outros agentes antitumorais ${ }^{7}$.

\section{Cisplatina}

Apesar de ter sido descrita há mais de 150 anos, só nos últimos 30 anos é que tem sido reconhecida como um potente agente antitumoral $^{38}$. O principal sítio de ligação é o N7 da guanosina, embora também ocorra interação covalente com a adenosina e citosina $^{6,7,9,10}$. Ressalta-se que a cisplatina exerce acentuada atividade antitumoral nos cânceres genitourinários, particularmente o testicular, ovariano e vesical; também é usada no tratamento de carcinomas escamosos, como de cabeça e pescoço, esôfago e cérvix, carcinoma de bexiga, tireóides, endométrio, estômago ou pâncreas, de pulmão de pequenas e não-pequenas células, sarcomas, tumores trofoblásticos e coriocarcinoma ${ }^{6-9}$.

\section{Carboplatina}

Análogo da cisplatina, apresenta em sua molécula o grupo dicarboxilato, que é mais estável. A sua ligação com as proteínas plasmáticas é menos irreversível que a da cisplatina e sua excreção também é mais rápida ${ }^{6,8,9}$. É uma alternativa útil para a cisplatina, uma vez que apresenta menor toxidez gastrointestinal e renal, porém com toxidez mielossupressiva ${ }^{7}$. Seu espectro de ação é semelhante ao da cisplatina, excetuando-se talvez os sarcomas e os tumores trofoblásticos, para os quais parece ser menos eficaz ${ }^{6-9}$. Mais recentemente, tem-se desenvolvido complexos diméricos análogos à cisplatina mas, apesar de muito promissores, ainda estão em fase inicial de investigação ${ }^{39}$.
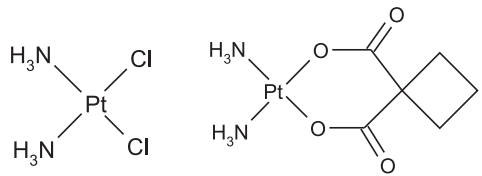

Figura 14. Estruturas da cisplatina e carboplatina

\section{Antibióticos naturais ${ }^{7-10}$}

Antraciclinas: Representam uma importante classe de antibióti$\cos$ antitumorais ${ }^{40}$. Evidências sugerem que as antraciclinas apresentam três mecanismos de ação. Um seria pela formação de ligações com os grupos fosfolipídeos (carregados negativamente) da membrana celular, alterando sua fluidez, assim como o transporte de íons. Também promoveriam a formação do radical livre do oxigênio e da semiquinona, através de um processo redutor enzimático. Um outro modo de ação seria a formação de ligações interfilamentares com o DNA, o que leva ao bloqueio da síntese do DNA e RNA e diminuição da atividade da topoisomerase II, promovendo a ruptura dos filamentos da macromolécula (DNA) ${ }^{7,41}$. Apesar de usualmente estes antibióticos serem classificados como agentes intercalantes do DNA (que serão discutidos posteriormente neste trabalho) estudos mais recentes evidenciam que, além da intercalação, há a formação de adutos de estrutura complexa por ligações covalentes com o DNA ${ }^{42}$. Os seus congêneres, doxorrubicina e daunorrubicina (Figura 15) foram aprovados pela "FDA - Food and Drug Administration" para uso geral ${ }^{7}$.

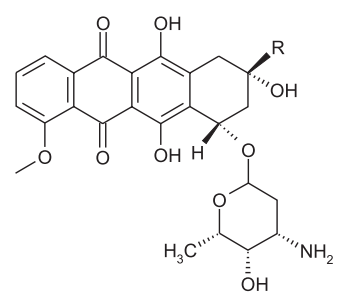

$$
\begin{array}{ll}
\text { Daunorrubicina } & \mathrm{R}=\mathrm{CH}_{3} \mathrm{CO} \\
\text { Doxorrubicina } & \mathrm{R}=\mathrm{HOCH}_{2} \mathrm{CO}
\end{array}
$$

Figura 15. Estruturas de Daunorrobicina e Doxorrubicina

Mitomicina: A mitomocina C (Figura 16) é um antibiótico isolado de Streptomyces caespitosus. É um agente alquilante biorredutor, que sofre ativação redutora metabólica enzimática ${ }^{5}$. Os metabólitos formados alquilam o DNA através de ligações cruzadas, similares às formadas com alcalóides pirazolidínicos (que serão mostrados posteriormente), mas de maior complexidade ${ }^{43-45}$. Estes compostos favorecem a produção de superóxidos, que promovem danos de caráter oxidativo no $\mathrm{DNA}^{46}$. 
<smiles>CC1=C(N)C(=O)C2=C(C1=O)N1CC3NC(C2OC(N)=O)C1OCC3C</smiles>

Figura 16. Estrutura da Mitomicina $C$

Dactinomicina (Actinomicina D, Coesmegen) (Figura 17): Antibiótico antitumoral isolado de Streptomyces. Liga-se fortemente ao DNA, através de sua intercalação entre pares de bases adjacentes de guanina-citosina. Inibe todas as formas de síntese de RNA DNAdependentes, sendo a formação de RNA ribossômico mais sensível à ação do fármaco. A replicação do DNA não é tão reduzida, porém a síntese de proteínas é bloqueada?

Plicamicina (Mitramicina, Mithracin) (Figura 17): É outro antibiótico natural usado no tratamento do câncer, cujo mecanismo de ação parece envolver a ligação do fármaco ao DNA através de um complexo antibiótico- $\mathrm{Mg}^{2+}$. Esta interação interrompe a síntese de RNA dirigida pelo DNA.

Bleomicina (Figura 17): Sua ação deve-se à ligação do fármaco ao DNA, produzindo quebras filamentares e inibição da sua síntese. Mesmo que o efeito citotóxico deste antibiótico esteja relacionado à formação de ligações com o DNA, este fármaco é classificado como CCS, uma vez que provoca um acúmulo de células em $\mathrm{G}_{2}$.

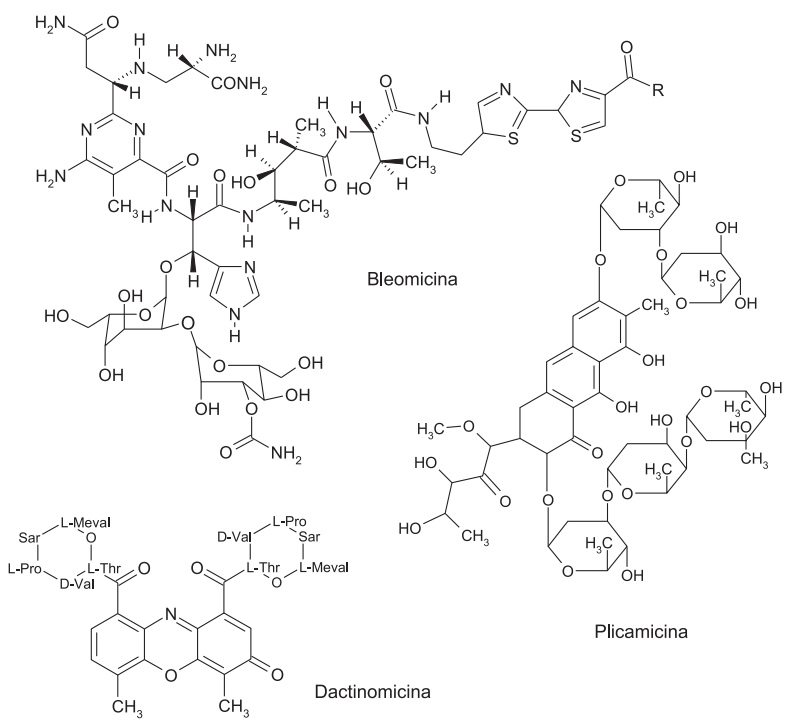

Figura 17. Estruturas da Dactinomicina, Plicamicina e Bleomicina

Alcalóides pirrolizidínicos: apresentam-se como potentes antitumorais (pró-fármacos), uma vez que os produtos de seu metabolismo oxidativo promovem a formação de ligações cruzadas do tipo DNA-proteína ${ }^{47}$ (Figura 18). O N-óxido da Indicina possui potente atividade antitumoral. $\mathrm{O}$ grau de hepatoxicidade apresentado por este fármaco é mínimo, quando comparado com os outros alcalóides pirrolizidínicos. Isto se deve à preferência em formar ligações cruzadas do tipo DNA-proteínas, do que ligações cruzadas interfilamentares (após metabolismo oxidativo) ${ }^{10}$. Em geral, os alcalóides pirrolizidínicos cíclicos (de 12 membros) $\alpha, \beta$-insaturados são mais potentes que seus análogos acíclicos. A presença da insaturação em $\alpha, \beta$ também é importante na diferença de potência observada. Não se conhece como a presença do ciclo e a insaturação influenciam na potência destes alcalóides ${ }^{19,48}$.
Diésteres Macrocíclicos<smiles>C=C(C/C(=C/C)C(=O)OC1CCN2CCCC12)C(=O)OCC1CCCC1</smiles>

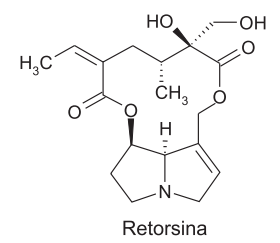<smiles>[R6]C1CCC(OC(=O)C(=CC)CC(=C)C(O)(CO)C(=O)OCC2=CCN3CCCC23)C1</smiles><smiles>C/C=C(/CC[C@@H](O)C(C)(C)O)C(=O)OCC1=CCN2CCCC12</smiles><smiles>C[C@H](O)C(=O)OCC1=CCCN1CCC1OC(=O)[C@@H](C)[C@H](O)C1(C)O</smiles>

Diésteres Acíclicos<smiles>C/C=C(/C)C(=O)O[C@H]1CCN2CC=C(COC(=O)[C@@](C)(C(C)C)C(C)(C)O)[C@H]12</smiles><smiles>CC(C)[C@](O)(C(=O)OCC1=CCN2CCC(O)C12)C(=O)OCC1=CC[N+]2([O-])CCC(O)[C@@H]1C2</smiles>

Figura 18. Estruturas de alguns alcalóides pirrolizidínicos biologicamente ativos

Além dos agentes antineoplásicos acima citados, existem outros fármacos utilizados no tratamento clínico dos diferentes tipos de câncer, que provavelmente atuam como agentes alquilantes, entre eles a Procarbazina (N-metil-hidrazina, MIH, Natulanar $\left.{ }^{\circledR}\right)$, que é um derivado da metil-hidrazina, a Dacarbazina (DCIT-Home ${ }^{\circledR}$, Altretamina (Hexametilamina), Tiotepa (Trietilenotiofosforamida), Mitoxantrona (Novantrone ${ }^{\circledR}$ ). O Mitotano (o,p’-DDD, Lysodren ${ }^{\circledR}$ ) que é um supressor córtico-supra-renal, a Hidroxiuréia (Hydrea ${ }^{\circledR}$ ), análogo da uréia que inibe a síntese do DNA, e os derivados do ácido retinóico, Etretinato e Isotretinoína, são também utilizados como agentes antitumorais. Novos agentes antineoplásicos têm sido desenvolvidos e poderiam ser mostrados, mas ainda são muito recentes e por isto não serão aqui abordados ${ }^{7-10,19}$. Entretanto, cabe ressaltar os estudos mais recentes e promissores sobre os agentes quimioterápicos antineoplásicos intercalantes com o DNA.

\section{QUIMIOTERÁPICOS ANTINEOPLÁSICOS CICLO- CELULAR NÃO-ESPECÍFICOS (CCNS) QUE INTERAGEM COM O DNA POR INTERCALAÇÃO. LIGANTES NA FENDA MENOR. COMBILEXINAS}

Neste tipo de agente antineoplásico as moléculas têm como alvo principal a fenda menor do B-DNA, por um mecanismo de ação que se baseia na intercalação nos pares de base nitrogenadas CG (citosina e guanina $)^{49}$. A intercalação apresenta uma componente eletrostática relacionada à interação do tipo $\pi$, existente entre os intercalantes e as 
bases CG, além de complexos de transferência de elétrons. Devido a esta característica, os intercalantes são constituídos por anéis aromáticos fundidos, apresentando alta densidade eletrônica, Os antibióticos naturais tipo antraciclina, como a doxorrubicina e a daunorrubicina (Figura 15), como citado, também costumam ser classificadas como agentes intercalantes.

A presença de anéis aromáticos fundidos constituindo o arcabouço molecular também permite observar outra característica relacionada ao mecanismo de ação, que é o espaçamento das bases nitrogenadas do DNA. Os intercalantes interagem com as bases nitrogenadas CG provocando um espaçamento devido ao volume molecular, formando um ângulo de aproximadamente $90^{\circ}$ em relação ao eixo do DNA.

A intercalação geralmente altera a estrutura do B-DNA, com o aumento no espaçamento dos pares de base CG de 3,4 A para cerca de 7 A. É descrito que o mecanismo de ação desta classe baseia-se na formação de um trímero constituído pelo intercalante, DNA e topoisomerase $\mathrm{II}^{50}$. Este trímero seria estabilizado e interromperia a separação das bases nitrogenadas do DNA, necessária à transcrição (para os ligantes na fenda menor também seria observada esta característica). Algumas destas moléculas foram descritas como ativas, tendo como alvo biológico as topoisomerases I e II, entretanto a correlação entre a intercalação e a interação com a topoisomerase II ainda não foi definida, sendo objeto de diversos estudos recentes ${ }^{50}$.

Dentre as diversas substâncias com propriedade intercalante ao DNA, ressaltam-se algumas, como as antraciclinas (Figura 15), já relatadas em relação a outros possíveis mecanismos de ação, e outros antibióticos como as actinomicinas (Figura 17) ${ }^{49} \mathrm{e}$ as acridinas, como a própria acridina não-substituída e a proflavina (Figura 19).

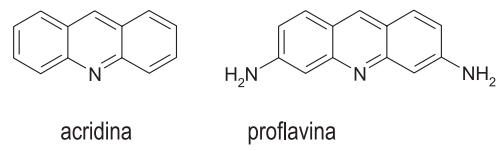

Figura 19. Estruturas de acridinas

\section{Ligantes na fenda menor}

Alguns agentes antineoplásicos interagem com os pares de bases nitrogenadas reversivelmente (por meio de contatos de van der Waals, interações eletrostáticas e, sobretudo, ligação hidrogênio), geralmente através de conformações tipo iso-hélicas e são classificados como moléculas ligantes na fenda menor do B-DNA ${ }^{51}$. A característica iso-hélica pode ser definida pela alteração conformacional destas moléculas, para que haja a interação com os pares de base nitrogenadas que compõem a hélice do B-DNA. As moléculas mais representativas dessa classe são as amidinas aromáticas ${ }^{52,53}$ e as lexitropsinas $^{51}$ (Figura 20).
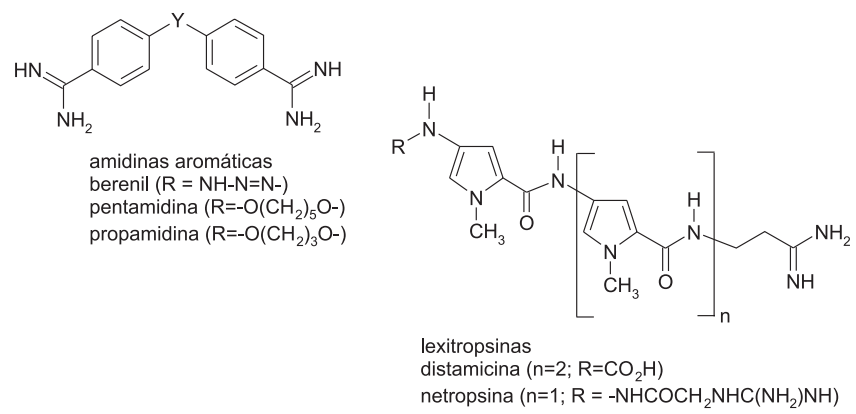

Figura 20. Estruturas de amidinas aromáticas e lexitropsinas
De fato, foi observado que em tal conformação iso-hélica, deve ocorrer possível interação com os pares de bases nitrogenadas do $\mathrm{DNA}^{54}$, descrita também nas estruturas cristalográficas ${ }^{55-59}$. Os ligantes na fenda menor interagem preferencialmente com os pares de base AT (adenina e timina), pois a guanina possui um substituinte, que é uma amina aromática, voltada para o interior da fenda menor, causando impedimento estereoquímico. Diversas modificações nas estruturas das amidinas aromáticas, distamicina e netropsina foram elaboradas $^{51}$, visando alterar a seletividade aos pares de base AT (adenina e timina) para CG (citosina e guanina), aumentar o número de bases que irão interagir, além de se tentar aumentar a afinidade das moléculas às sequiências AT do DNA. Estudos estão sendo feitos buscando entender uma possível interação destas moléculas com a topoisomerase $e^{60}$.

\section{Combilexinas}

São moléculas antitumorais que possuem dois mecanismos de ação presentes em uma molécula (intercalação e ligação na fenda menor do B-DNA) separados por um grupo espaçador ${ }^{61}$, Figura 21. As combilexinas foram planejadas a partir de modificações moleculares feitas em dois ligantes na fenda menor, a netropsina e a distamicina, com a finalidade de se entender o mecanismo de interação e também poder alterá-lo (como exemplo, tem-se lexitropsinas que interagem com pares de bases citosina e guanina $)^{62}$, havendo então a inclusão do fragmento relacionado ao intercalante. Entretanto, como este intercalante não deveria estar ligado diretamente ao ligante na fenda menor, o que inviabilizaria um dos mecanismos de ação, foi planejado o uso de um grupo espaçador ${ }^{62,63}$. Em sua maioria as combilexinas apresentam um mecanismo de ação predominante, onde ora o intercalante (maior afinidade pelas bases CG), ora o ligante na fenda menor (maior afinidade pelas bases AT) define a afinidade do híbrido pelo B-DNA. Não é bem compreendido o comportamento deste fenômeno, entretanto sabe-se que a afinidade pode estar relacionada à estabilidade e às condições de interação das duas subunidades no DNA, uma vez que as interações são bem próximas. Mais recentemente, vários tipos de combilexinas foram estudados com modificações em relação ao grupo espaçador e ao fragmento intercalante, com resultados promissores ${ }^{61,64-71}$.

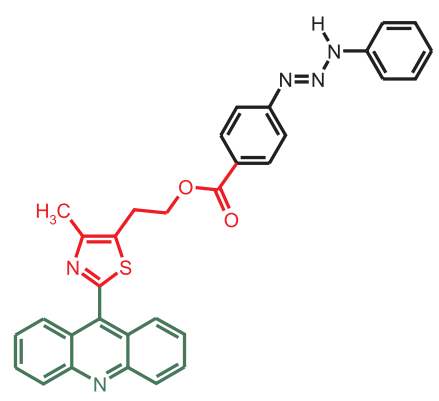

Figura 21. Estrutura molecular fundamental de algumas combilexinas tipo acridina-berenil

Existem na literatura alguns outros estudos de moléculas complexas, como ilustrado na Figura 22, mas o número de moléculas que pode, de fato, ser caracterizado como combilexina é pequeno, devido à definição de que apenas ligantes na fenda menor e agentes intercalantes podem constituir este tipo de molécula. Isto exclui outras moléculas híbridas, como os conjugados ligante na fenda menor-alquilante ${ }^{72-74}$, intercalante-ligante na fenda menor e alquilante, alquilante e intercalante ${ }^{75}$, além dos dímeros ${ }^{76}$. Os compostos cisplatina-distamicina e cisplatina-berenil são híbridos intercalantes- 
ligantes na fenda menor e a bis-acridina é, na verdade, um dímero da acridina.

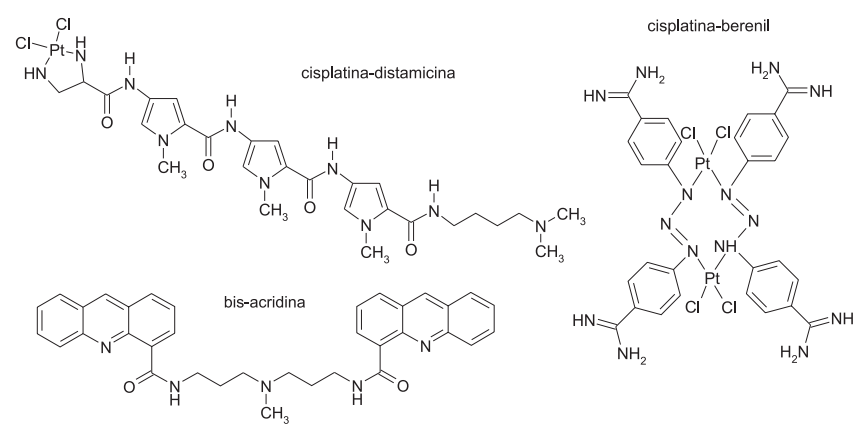

Figura 22. Estruturas moleculares de alguns híbridos antineoplásicos complexos que não pertencem à classe das combilexinas

\section{CONCLUSÕES}

A seguir são apresentadas, de uma forma geral ${ }^{3-9}$, as aplicações farmacológicas dos agentes quimioterápicos antineoplásicos mais utilizados, mostrando as nominações científicas destes agentes e correlacionando-os com as principais aplicações em tipos de neoplasias específicas, conforme a classificação dada inicialmente neste texto.

Usos clínicos

Carcinomas

de mama

Agente antineoplásico clinicamente usado

Melfalam, ciclofosfamida, mitomicina, daunorrubicina, doxorrubicina, podofilotoxinas (etoposida e teniposida), vimblastina, vincristina, antiandrogênios, antiestrogênios, estrogênios, metotrexato; taxol (casos avançados)

de ovário

Ifofosfamida, cisplatina, melfalam, clorambucil, fluorouracil, doxorrubicina, vincristina, tamoxifeno

endometrial Cisplatina, carboplatina, doxorrubicina, ciclofosfamida, isofosfamida, progestina, estrogênios, anti- estrogênios

de cólon Ciclofosfamida, fluorouracil

de próstata Fluorouracil, anti-androgênio, prednosona, doxorrubicina, hidroxiuréia, progestinas, estrogênios, androgênios, leuprolida, aminoglutetimida

de testículo

Cisplatina, plicamicina, dactinomicina, podofilotoxinas, ciclofosfamida, metotrexato, vimblastina, bleomicina, doxorrubicina

de bexiga

de pâncreas Cisplatina, doxorrubicina, vimblastina

de estômago

Cisplatina, carboplatina, mitomicina, fluorouracil

de esôfago Cisplatina, carboplatina, mitomicina, doxorrubicina

gastrointestinal Mitomicina

de cabeça e pescoço Cisplatina, carboplatina, doxorrubicina, fluorouracil, vincristina, vimblastina, bleomicina, metotrexato

de cérvix Cisplatina, doxorrubicina, mitomicina, vincristina, bleomicina de tireóide

de pulmão

de garganta e boca

Sarcomas

Linfomas

Melanonas

Neuroblastoma

Gliomas

Leucemias

Linfocítica

Mieloblástica

Linfoblástica

Mielocítica

Mielomonocítica

Linfática

Infantil

Mieloma
Cisplatina, carboplatina, melfalam, bleomi-

Cisplatina, carboplatina, doxorrubicina, mitomicina, vincristina, vimblastina, podofilotoxinas

Cisplatina e doxorrubicina dactinomicina, podofilotoxinas, metotrexato, ciclofosfamida, vincristina, vimblastina

Doxorrubicina, ciclofosfamida, ifosfamida, clorambucil, vincristina, vimblastina, podofilotoxinas, pentostatina (células T), retamina, dacarazina, carmustina

Ciclofosfamida, dactinomicina, doxorrubicina, vimblastina

Citarabina

Vincristina (casos agudos), clorambucil, metotrexato, predsinona, carmustina (aguda e crônica), doxorrubicina

Tioguanina, citarabina, podofilotoxinas

Vincristina, podofilotoxinas

Metotrexato, vincristina, mercaptopurina, hidróxiuréia

Vincristina, mercaptopurina

Clorambucil

Aspariginase

Melfalam e vincristina cina, fluorouracil

Cisplatina, ciclofosfamida, doxorrubicina, prednisona, citarabina, bleomicina, meclo-

Mitomicina e dacarbazina

Estes dados demonstram que há uma ampla utilização clínica dos agentes antineoplásicos quimioterápicos que interagem com o DNA para as diversas neoplasias, o que comprova a enorme importância desta classe de fármacos e corrobora o grande interesse acadêmico e tecnológico no desenvolvimento de novos análogos mais eficientes e menos tóxicos. Além do mais, em vários casos, a seletividade e eficiência destes agentes antineoplásicos tem sido aumentada por uso de mecanismos de liberação controlada ou de citoproteção ${ }^{77}$. Contudo, apesar da ampla utilização clínica dos agentes quimioterápicos antineoplásicos, especialmente os agentes alquilantes, que conseguem muitas vezes controlar o crescimento tumoral e até prolongar a vida dos pacientes em vários anos, os oncologistas afirmam que a melhor ajuda para combater o câncer não é o tratamento antineoplásico, mas o diagnóstico precoce e, principalmente, a sua prevenção.

\section{REFERÊNCIAS}

1. Ministério da Saúde; Mensagem aos médicos. Câncer Fundamentos, Secretária de Asistência Médica-Divisão Nacional de Câncer; Brasília, 1971, p. 7-47.

2. http://www.inca.org.br/cancer, acessada em Junho 2003.

3. Spence, R. A. J.; Jonhston, P. G. Em Oncology; Jonhston, P. G., ed; Oxford University Press: Oxford, 2001, p. 1-14, 121-132; Chabner, B. A.; Longo, D. L. Em Cancer chemotherapy and biotherapy; 2a . ed., Lippincott-Raven: Filadélfia, 1996.

4. Foye, W. O.; Sengupta, S. K. Em Principles of Medicinal Chemistry; Foye, W. O.; Lemke, T. L.; Williams, D. A., eds.; Williams \& Wilkins: Baltimore, 1996, p. 822-845.

5. Murad, A.M.; Katz, A.; Oncologia Bases Clínicas do Tratamento; Guanabara; Rio de Janeiro, p. 41.

6. Machado, A. E. D.; Quim. Nova 2000, 23, 237.

7. Salmonm, S.E. Em Farmacología Básica \& Clínica, Katzung, B.G., ed.; Guanabara Koogan S.A.: Rio de Janeiro, 1998, p. 629-655.

8. Oliveira, R. B.; Alves, R. J.; Quim. Nova 2002, 25, 976. 
9. Chabner, B. A.; Calabresi, P. Em As Bases Farmacológicas da Terapêutica; Goodman, L. S.; Gilman, A., eds.; Mc Graw Hill: Rio de Janeiro, 1995, p. 903-949.

10. Hahn, W. C.; Weinberg, R. A.; Nat. Rev. Cancer 2002, 2, 331.

11. Zhou, B. -B. S.; Elledge, S. J.; Nature 2000, 408, 433.

12. Jäger, E; Jäger, D.; Knuth, A.; Curr. Opin. Immunol. 2002, 14, 178.

13. Keskin, O.; Bahar, I.; Jeringan, R. L.; Beutler, J. A.; Shoemaker, R. H.; Sausville, E. A.; Covell, D. G.; Anti-Cancer Drug Des. 2000, 15, 79.

14. Iida, H.; Jia, G.; Lown, J. W.; Curr. Opin. Biotechnol. 1999, 10, 29.

15. Dervan, P. B.; Bioorg. Med. Chem. 2001, 9, 2215.

16. Krugh, T. R.; Curr. Opin. Struct. Biol. 1994, 4, 351

17. Silverman, R. B.; The Organic Chemistry of Drug Design and Drug Action, Academic Press Inc.: San Diego, 1992, cap. 3, 4, 6, 7.

18. Lehninger, A. L.; Nelson, D. L.; Cox, M. M.; Principles of Biochemistry, $3^{\text {rd }}$ ed., Worth Publisnhing: New York, 2000.

19. Rajski, S. R.; Williams, R. M.; Chem Rev. 1998, 98, 2723

20. Montanari, C. A.; Trent, J. O.; Jenkins, T. C.; J. Braz. Chem. Soc. 1998 9,175.

21. Antonini, I.; Polucci, P.; Kel1and, L. R.; Spinel1i, S.; Pescalli, N.; Martelli, S.; J. Med. Chem. 2000, 43,4801.

22. Antonini, I.; Polucci, P.; Magnano, A.; Martel1i, S.; J. Med. Chem 2001 $44,3329$.

23. Auparakkitanon, S.; Wilairat, P.; Biochem. Biophys. Res. Commun. 2000, 269, 406.

24. Hopkins, P. B.; Millard, J. T.; Woo, J.; Weidner, M. F.; Kirchner, J. J.; Sigurdsson, S. T.; Raucher, S.; Tetrahedron 1991, 47, 2475; Kohn, K. W. Em Topics in Structural \& Molecular Biology: 3) Molecular Aspects of Anti-cancer Drug Action; Neidle, S., Waring, M., eds.; Verlag Chemie: Weinheim, 1994, p. 315; Lawley, P. D.; BioEssays 1995, 17, 561; Gniazdowski, M.; Cera, C.; Chem. Rev. 1996, 96, 619; Paustenbach, D. J.; Finley, B. L.; Kacew, S.; Proc. Soc. Exp. Biol. Med. 1996, 211, 211.

25. Brookes, P.; Lawley, P. D.; Biochem. J. 1961, 80, 496.

26. Rink, S. M.; Hopkins, P. B.; Biochemistry 1995, 34, 1439.

27. Holley, J. P.; Mather, A.; Wheelhouse, R. T.; Cullis, P. M.; Hartley, J. A.; Bingham, J. P.; Cohen, G. M.; Cancer Res. 1992, 52, 4190.

28. Prakash, A. S.; Denny, W. A.; Gourdie, T. A.; Valu, K. K.; Woodgate, P. D.; Wakelin, L. P. G.; Biochemistry 1990, 29, 9799.

29. Gilman, A.; Phillips, F. S.; Science 1946, 103, 409; Haskel, C. M.; Cancer Treatment, Saunders: Philadelphia, 1990.

30. Prakash, S. S.; Gibson, N. W.; Carcinogenesis 1992, 13, 425; Gibson, N. W.; Hartley, J. A.; Barnes, D.; Erickson, L. C.; Cancer Res. 1986, 46, 1943; Tong, W. P.; Cancer Res. 1982, 42, 3102.

31. Levin, V. A.; Wilson, C. B.; Cancer Treat. Rep. 1976, 60, 719; Prestayko, A. W.; Crooke, S. T.; Bakeer, L. H.; Carter, S. K.; Schein, P. S. Em Nitrosoureas: Current Status and New Developments, Prestayko, A. W., ed.; Academic Press: New York, 1981.

32. Hartley, J. A.; Fox, B. W.; Cancer Chemother. Pharmacol. 1986, 17, 56; Pacheco, D. Y.; Cook, C.; Hincks, J. R.; Gibson, N. W.; Cancer Res. 1990, 50, 7555; ibid, 1989, 49, 5108

33. Brookes, P.; Lawley, P. D.; Biochem. J. 1961, 80, 496.

34. Tong, W. P.; Ludlum, D. B.; Biochim. Biophys. Acta 1980, 608, 174

35. Brouwer, J.; Vandeputte, P.; Fichtingerschepman, A. M. J.; Reedijk, J.; J. Proc. Natl. Acad. Sci. Biol. USA 1981, 78, 7010; Bubley, G.J.; Ashburner, B. P.; Teicher, B. A.; Mol. Carcinog. 1991, 4, 397; Cariello, N. F.; Swenberg, J. A.; Skopek, T. R.; Cancer Res. 1992, 52, 2866.

36. Corda, Y.; Job, C.; Anin, M. F.; Leng, M.; Job, D.; Biochemistry 1993, 32, 8582; Brown, S. J.; Kellett, P. J.; Lippard, S. J.; Science 1993, 261, 603; Treiber, D. K.; Zhai, X. Q., Jantzen, H. M.; Essigmann, J. M.; Proc. Natl. Acad. Sci. U.S.A. 1994, 91, 5672; Pil, P. M.; Lippard, S. J.; Science 1992, $256,234$.

37. Kutyavin, I. V., Gamper H.B., Gall A. A., Meyer R.B.; J. Am. Chem. Soc. 1993, 115, 9303 .

38. Reeddijk, J.; J. Chem. Soc., Chem. Commun. 1996, 801; Shermnan, S. E.; Lippard, S. J.; Chem. Rev. 1987, 87, 1153; Lippard, S. J. Em Platinum and Other Metal Coordination Compounds in Cancer Chemoterapy; Howell, S. B., ed.; Plenum Press: New York, 1991, p. 1-10.

39. Farrell, N.; Appleton, T. G.; Qu, Y., Roberts, J. D.; Fontes, A. P. S.; Skov, K. A.; Wu, P.; Zou, Y.; Biochemistry 1995, 34, 15480

40. Cullinane, C.; Cutts, S. M.; Vanrosmalen, A.; Phillips, D. R.; Nucleic Acids Res. 1994, 22, 2296.

41. Cummings, J.; Cohen, A. S.; Hulse, R.; Post, D. E.; Redi, M. H.; Perkins, J.; Eur. J. Cancer 1991, 27, 532.
42. Wang, A. H.-J.; Ughetto, G.; Quigley, G. J.; Rich, A.; Biochemistry 1987, 26, 1152; Wang, A. H.-J. Em Molecular Aspects of Anticancer Drug-DNA Interactions; Neidle, S.; Waring, M., eds.; CRC Press: Boca Raton, 1993, p. 35-38.

43. Komiyama, T.; Kikuchi, T.; Sugiura, Y.; Biochem Pharmacol. 1982, 31, 3651; Lown, J. W.; Mol. Cell. Biochem. 1983, 55, 17; Sartorelli, A. C.; Pritsos, C. A.; Cancer Res. 1986, 46, 3528; Hamana, K.; Biochem. Int. 1985, 10, 31

44. Verdine, G. L.; Chem. Biol. 1997, 4, 329.

45. Egbertson, M.; Danishefsky, S. J.; J. Am. Chem. Soc. 1987, 109, 2204.

46. Choi, Y. H.; Park, A.; Schmitz, F. J.; Vanaltena, I.; J. Nat. Prod. 1993, 56, 1431; Schimitz, F. J.; Park, A.; Tetrahedron Lett. 1993, 3983.

47. Kim, H. Y.; Carcinogenesis 1995, 16, 2691.

48. Kim, H. Y.; Stermitz, F. R.; Molyneux, R. J.; Wilson, D. W.; Taylor, D.; Coulombe, R. A.; Toxicol. Appl. Pharmacol. 1993, 122, 61.

49. Bodel, W. J.; Chen, F. X.; Zhang, Y.; Church, K. M; Carcinogenesis 1993, 14, 935; Caonfalone, P. N.; Huie, E. M.; Ko, S. S.; Cole, G. M.; J. Org. Chem. 1988, 5, 482; Norman, D.; Live, D.; Sastry, M.; Lipman, R.; Hingerty, B. E.; Tomasz, M.; Broyde, S.; Patel, D. J.; Biochemistry 1990, 2, 2861; Geierstanger, B. H.; Volkman, B. F.; Kremer, W.; Wemmer, D. E.; Biochemistry 1994, 33, 5347; Pommier, Y.; Kohl-hagen, G.; Bailly, C.; Waring, M.; Mazumder, A.; Kohn, K. W.; Biochemistry 1996, 35, 13303.

50. Poot, M.; Killer, K-H.; Experimental Cell Research 1995, 218, 326.

51. Neidle, S.; Nat. Prod. Rep. 2001, 36, 291.

52. Neidle, S.; Kelland, L. R.; Trent, J. O.; Simpson, I. J.; Boykin, D. W.; Kumar, A.; Wilson, W. D.; Bioorg. Med. Chem. Lett. 1997, 7, 1403.

53. Cory, M.; Tidwell, R. R.; Fairley, T. A.; J. Med. Chem. 1992, 35, 431

54. Brown, D. G.; Sanderson, M. R.; Skelly, J. V.; Jenkins, T. C.; Brom, T.; Garman, E.; Stuart, D. I.; Neidle, S.; EMBO J. 1990, 9, 1329.

55. Brown, D. G.; Sanderson, M. R.; Garman, E.; Neidle, S.; J. Mol. Biol. 1992, $226,481$.

56. Laughton, C. A.; Tanious, F.; Nunn, C. M.; Boykin, D. W.; Wilson, W. D.; Neidle, S.; Biochemistry 1996, 35, 5655.

57. Nunn, C. M.; Garman, E.; Neidle, S.; Biochemistry 1997, 36, 4792.

58. Edwards, K. J.; Jenkins, T. C.; Neidle S.; Biochemistry 1992, 31, 7104.

59. Lowe, P. R.; Sansom, C. E.; Schwalbe, C. H.; Stevens, M. F. G.; J. Chem. Soc., Chem. Commun. 1989, 1164.

60. Rodrigues, R. F.; Lopes, J. C. D.; Montanari, C. A.; Quant. Struct.-Act. Relat. 2000, 19, 173.

61. McConnaughie, A. W.; Jenkins, T. C.; J. Med. Chem. 1995, 38, 3438.

62. Bailly, C.; Chaires, J. B.; Bioconjugate Chem. 1998, 9, 513.

63. Bailly, C.; Hénichart, J.-P.; Bioconjugate Chem. 1991, 2, 379.

64. Eliadis, A.; Phillips, D. R.; Reiss, J. A.; Skorobogaty, J. Chem. Soc., Chem. Commun. 1988, 1049.

65. Bailly, C.; Pommery, N.; Houssin, R.; Hénichart J.-P.; J. Pharm. Sci. 1989, 78, 910.

66. Subra, F.; Carteau, S.; Pager, J.; Paoletti, J.; Paoletti, C.; Auclair, C.; Biochemistry 1991, 30, 1642.

67. Subra, F.; Mouscadet, J. F.; Lavignon, M.; Roy, C.; Auclair, C.; Biochem. Pharmacol. 1993, 45, 93.

68. Goulaouic, H.; Carteau, S.; Subra, F.; Mouscadet, J. F.; Auclair, C.; Biochemistry 1994, 33, 1412

69. Bailly, C.; O’Huigin, C.; Houssin, R.; Colson, P.; Houssier, C.; Rivalle, C.; Bisagni, E.; Hénichart, J.-P.; Waring, M. J.; Mol. Pharmacol. 1992, 41, 845 .

70. Bourdouxhe, C.; Colson, P.; Houssier, C.; Sun, J-S.; Montenay-Garestier, T.; Hélène, C.; Rivalle, C.; Bisagni, E.; Waring, M. J.; Hénichart, J-P.; Bailly, C.; Biochemistry 1992, 31, 12385

71. Hénichart, J.-P.; Waring, M. J.; Riou, J.-F.; Denny, W. A.; Bailly, C.; Mol. Pharmacol. 1997, 51, 448.

72. Kostrhunova, H.; Brabec, V.; Biochemistry 2000, 39, 12639.

73. González, V. M.; Amo-Ochoa, P.; Pérez, J. M.; Fuertes, M. A.; Masaguer, J. R.; Navarro-Ranninger, C.; Alonso, C.; J. Inorg. Biochemistry, 1996, 63, 57.

74. González, V. M.; Pérez, J. M.; Alonso, C.; J. Inorg. Biochemistry 1997, 68, 283.

75. Ferguson, L. R.; Turner, P. M.; Denny, W. A.; Mutat. Res. 2000, 469, 115. 76. Garg, R.; Denny, W. A.; Hansch, C.; Bioorg. Med. Chem. 2000, 8, 1835.

77. Gabizon, A.; Shmeeda, H.; Barenholz, Y.; Clinic Pharmacokinetic 2003, 42, 419; Koukourakis, M. I.; Anticancer Drugs 2002, 13, 181. 